РЕЗУЛЬТАТЬ ЛЕЧЕНИЯ ТУБЕРКУЛЕЗА

С МНОЖЕСТВЕННОЙ И ШНРОКОЙ ЈЕКАРСТВЕННОЙ УСТОЙЧИВОСТЬЮ ВОЗБУДИТЕЛЯ И ЭФФЕКТИВНОСТЬ РЕЗЕКЦИОННОЙ ХИРУРГИИ У ПАЦИЕНТОВ С ФАКТОРАМИ РИСКА НЕБЛАГОПРИЯТНЫХ ИСХОДОВ

\author{
Я Р БАТЫРШНHА, В А КРАСНОВ.T И ПIЕTРEНКО

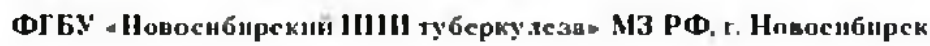

Выполнено ретроспективное когортное исследование $с$ цельо оценки исходов лечения 476 больных туберку.лезом $c$ множественной I широкой лекарственной устойчивостью вобоу дите.яя, внявления факторов риска неб́лагоприятньх мсходов и оценки в.лияния резекционньх хирургичегких вмешательств на резу.льтаты лечения. Излечение достигнуто у $71,8 \%$ больншх, у 22,7\% - лечение неаффективно, 5.5\% - умерли во время лечения. Основными предикторами неблагоприятншх исходов были наличие деструктивных изменений в лег ких (отношение шансов (ОШІ) 10,0; 95\%-ный дЫ 2,4-41,9), рас пространенность туберкулеаного процесса более 2 сегментов .етких (ОШГ 6,8;

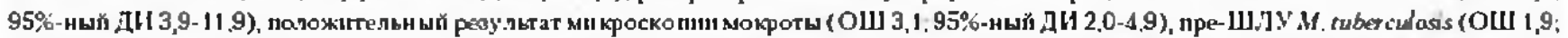

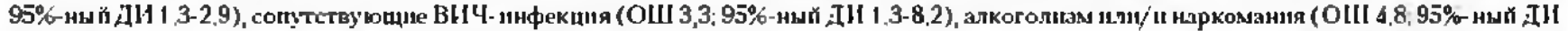

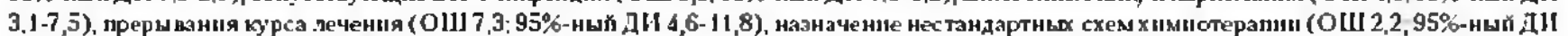

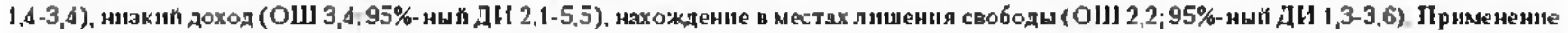

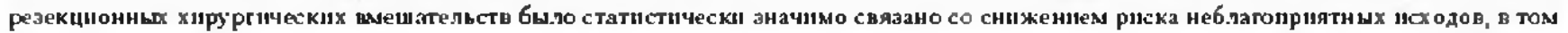
числе у пациентов с предикторами неудачи лечения.

Ключевое слова туберк' лез с множественной и широкой лекарственной устойчивостью, хирургическое лечение ту беркулева, резекционнше хируртические вмешательства.

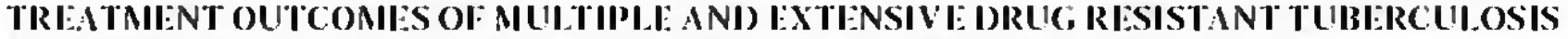 ANI) IEFIFIENCY OIF SUIRGICAL RESICCTIONS IN PATIIENTS WITII IIGII RISK OF LINFIVORABIIEOUTCONIES
}

\author{
YA R BATYRSHINA, V A KRASNOV,T I PETRENKO
}

Nowosibirsk Tubcreulosis Research Inst itute. Novosibirsk. Russia

The retrospective cohort study was aimed to evaluate trealment outcomes of 476 patients suftering from multiple and extensive dnig resistance, co detect risk factors of unlavorable outcomes and to assess $t$ he impact of surgical resections on I reat ment outcomes, $718 \%$ of patients were cured, in $22.7 \%$ treatment tailed, and $5.5 \%$ died during $t$ reac ment Main predictors of the undworable outcome were destructive changes in the lungs (Odds ratio (OR) 10.0,95\% Cl 24-419), more than 2 segments of the lungs aflected by tuberculosis (OR 6 8; 95\%-C13 9-119). positive results of sputum smear microscopy (OR 3 1.95\% CI 2.0-49), pre-X DR of $M$, tuberaslasis (OR 19,95\% CI 1.3-29), concurnent HIV infection (OR 3.3 : 95\% CI $13-82$ ), addiction to alcohol and/or substances (OR $48 ; 95 \% \mathrm{Cl}$ 31-75), treat ment interruption (OR 7 3: 95\% CI 4 6-118). prescription of non-standard chemotherapy regimens (OR 2.2,95\% CI 1 4-3.4), low income (OR 3.4:95\% Cl 2, 1-5.5), incarceration (OR 2 2:95\% CI $13-3.6$ ) Regarding st at ist ical sig nificance the use of surgical nesect ions was related to the reduction of the ris $x$ of unfwor able outcomes al so among the patients with treatment lailure predictors

Key soords Multiple and extensive drug resistant tuberculosis, su rgical treatment of tuberculosis, resections.

С начала мониторинга туберкулеза с миожествениої лекарствениої устоіјнивостью возбудн-

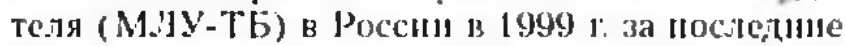
15 лет доля си возросла в 3.2 раза - с 6.7 , до $21.1 \%$ (2013 г) среди виервые выянленинх больных туберкулезом органов дыхания (ТO) с бактерновыделением и и 3.8 раза - с 10.5 до $40.0 \%$ срели пащиентов, состоящих на дисиансерном учете [5. 6]. 13 Новосибнрскої области этн показителин к 2013 r. достигли 31.2 ॥ $53.1 \%$ соответствен1н |2|. 1 lo ; дан-

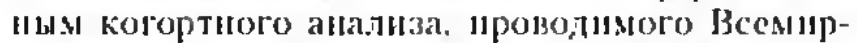
пой орraинзациеіі здравоохрансния (ВО3). в 2010 и 2011 г. глобально в мире излечене достилуто

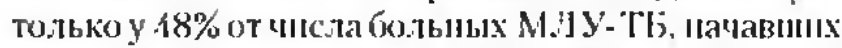
лечсние, в России - у 13 и 37\%, и Новосни́ирскої области - у 48.6 I $46.4 \%$ соответственно [2. 13 .

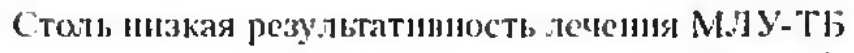
является одн1нм из основиых иренятстниї для әф()ективного контроля за туберку лезом ну улучнения эnн, темн1ескої cнтуанын.

13 современиых мсжлународиых руконодствах но ирограммному ведению M.IУ-ТБ̈ рекомендаIин1 но нрименени хируртнеского лечения огра-

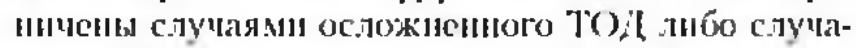
яІм11 туберкулеза с лекарстнениої устоїнивостью (.1У) возбудителя. конда нозможности этиотропної терании нсчернаны |4]. Тем не менее в нослетине голи в отечествениой 11 зарубежної литературе появ.ляются публнканин. " которых указывается на возастание роли хирургического лечения в условиях роста расиространености туберкулеза с М.IУ/11. 


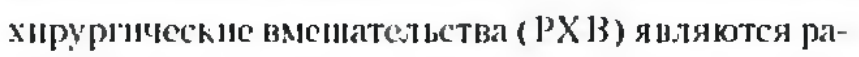

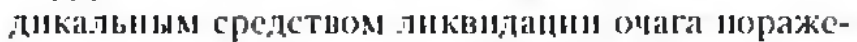

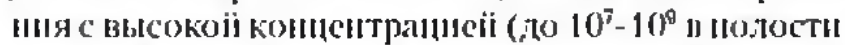

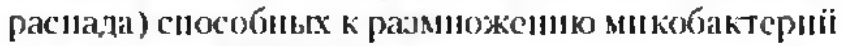

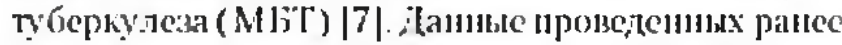

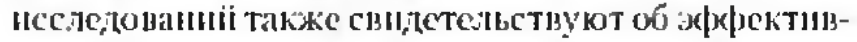

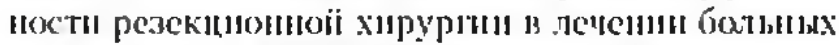

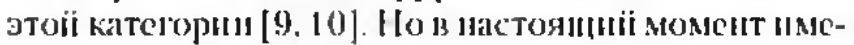
когся только однн снстематнесскиї обзор 11 мета-

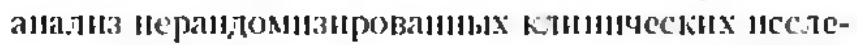

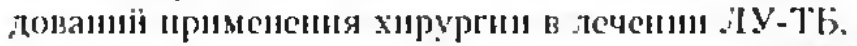
соответствукщце уровню доказательности $2|8|$.

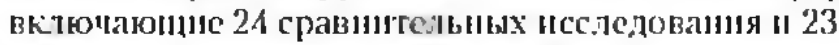

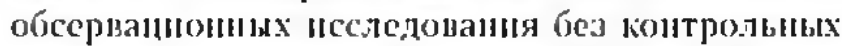

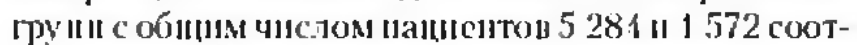

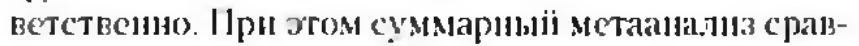

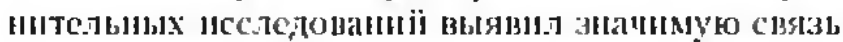

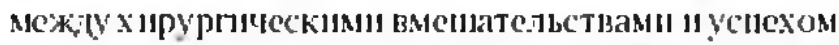
лечсия .5 Cуммарны

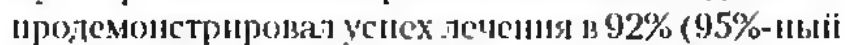

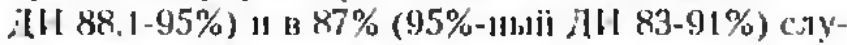

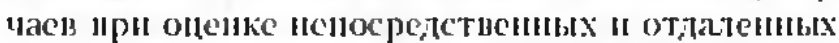

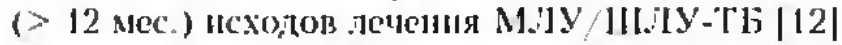

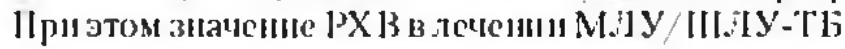
в настоя щее время ие яв.яется полиостью ошреде-

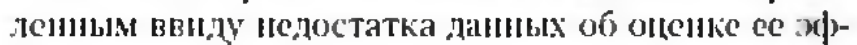

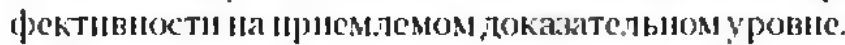

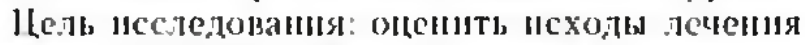

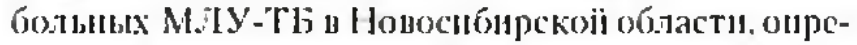

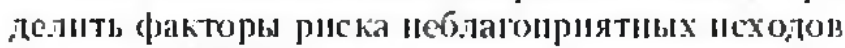

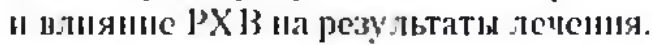

\section{Maтеринлы иметоды}

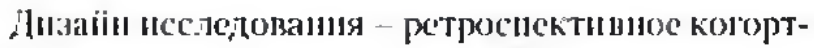

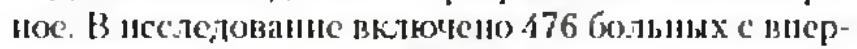

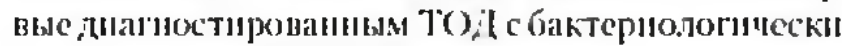

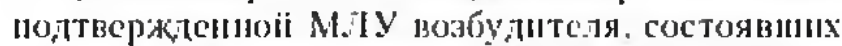

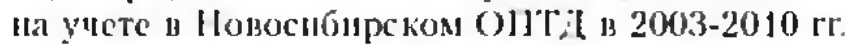

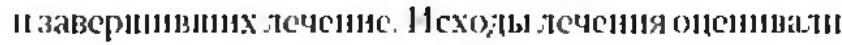

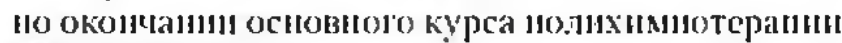

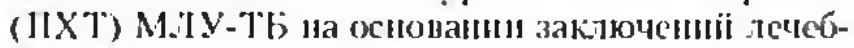

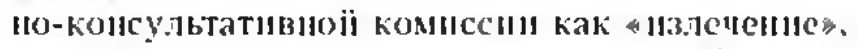

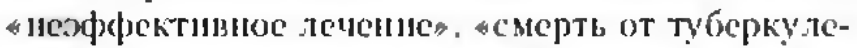

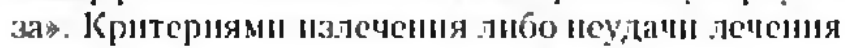

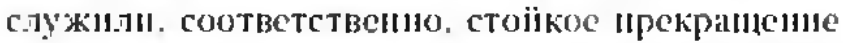
либо лаллячие бактерловыделения, отсутетвые либо

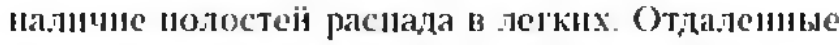
исходы дечения в сроки от I до 5 дет ирослежены у 291 болыных.

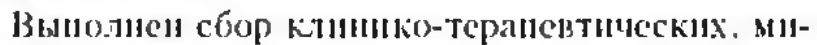

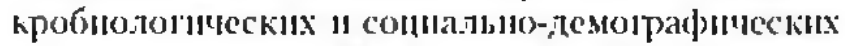

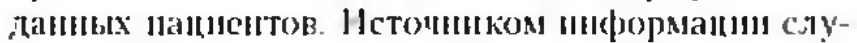

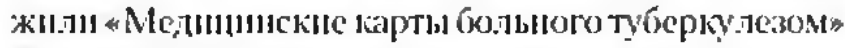

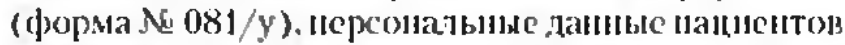

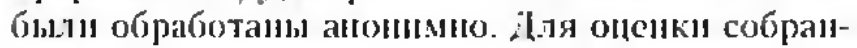
ных даныы как потенщиалыных ф)акторов рыска

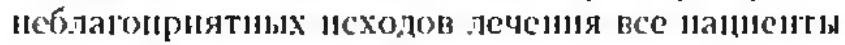

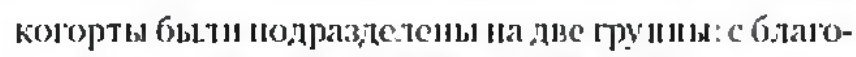

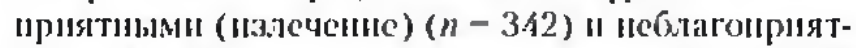

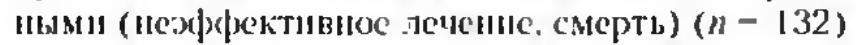

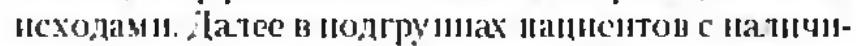

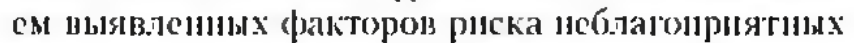

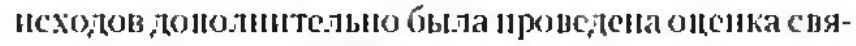

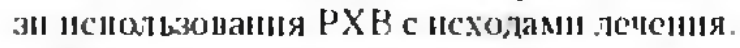

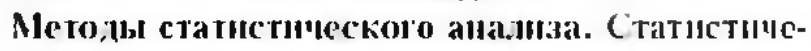

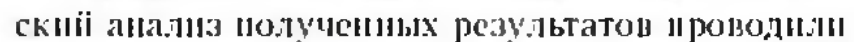

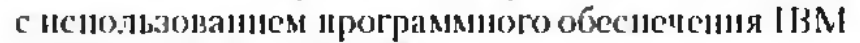

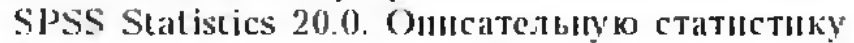

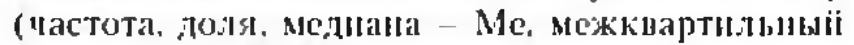
แ1тервал - МКИ) нснользошати дія характернстики выборкн. нелосредствениых и отдатенын

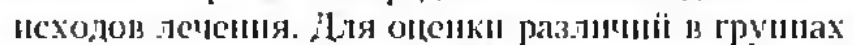

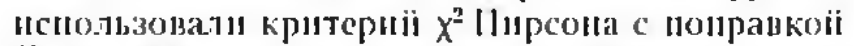

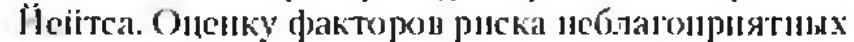

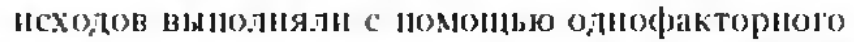

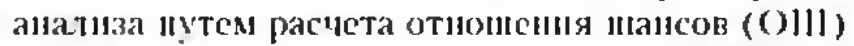

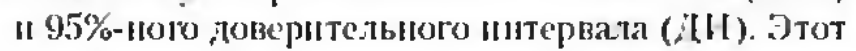
же Iоказатель псшот,зонат11 в качестве меры свя-

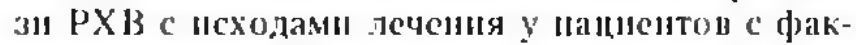

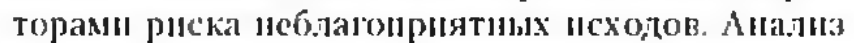

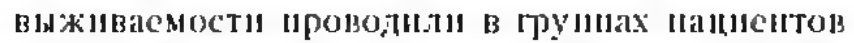

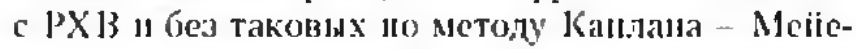
ра. д1я оценки различиї выжишасмости в групиах

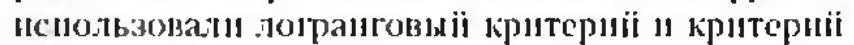
lexala - Бреслtoy - Bu.7kokcola. llpu ucex serodax

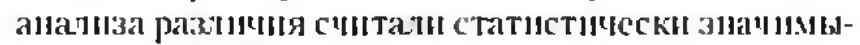
s11 I1p11 $p<0.05$.

\section{Результаты нсследования}

Хapakтеристика lioropto. Ochombыe combanb-

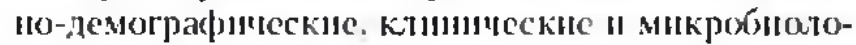
гическис параметры пациентои когорты ирелстан-

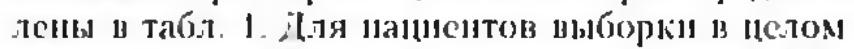
характерио щреобладание расщространенщих (60-

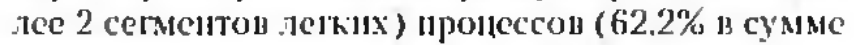
с двустороншими норажешиями), деструктиныње

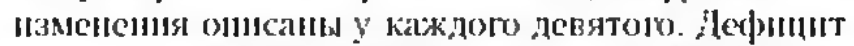

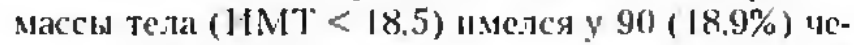

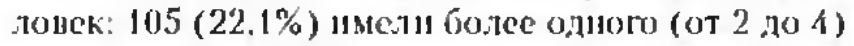
coryтс гву ющцето забојевания.

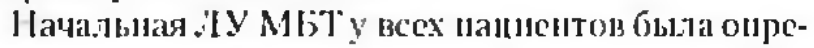

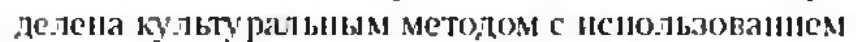

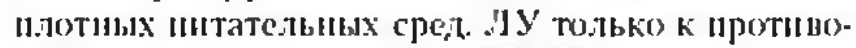
туберкулсзыым щреларатам (II011) 1-1'о ряда отмс-

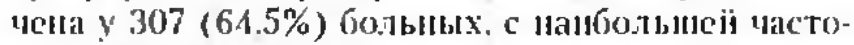
тоiі - 281/476 (59.7\%) - встрена.]ас' устоїчнвость

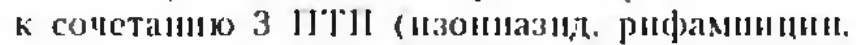

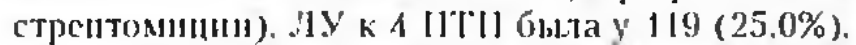
к $5-$ y $43(9,0 \%)$ к $6-$ y $21(1,1 \%), \kappa 7-y 6(1.3 \%)$. к $8-y 2(0.4 \%) .19-y^{\prime}(0.2 \%) 60.16$ Holo.

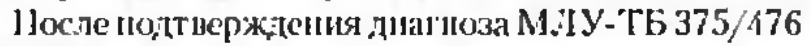
(78.8\%) палиситам выборки были назиачешы стан-

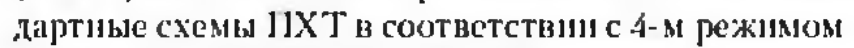
прнказа № $109 \mathrm{M} 3 \mathrm{PCD}(1.10 / 375)$ нти рекомендованиыс 1303 (235/375): $101 / 476(21.2 \%)$ болыным []XT 


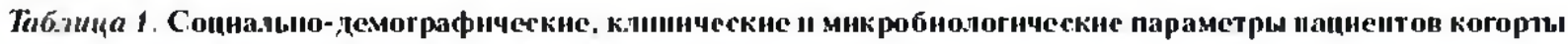
Tabte 1 . Social, demographic, clinical and microbiolo gical charaeteristics of t be cobort

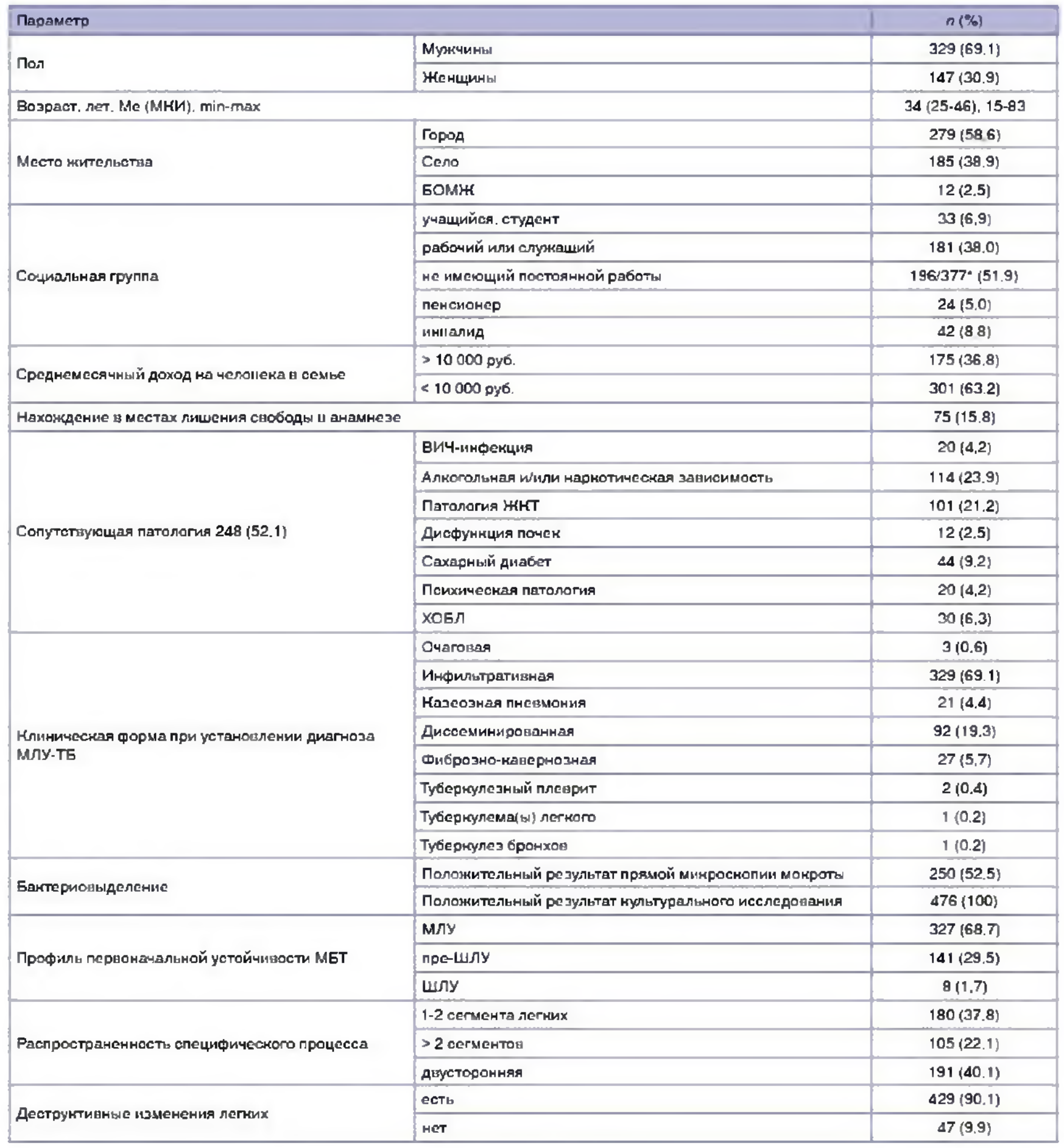

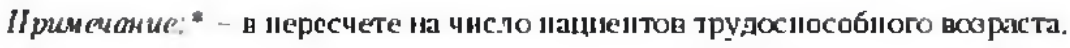

проводнли по ицдивидуализнрованиым режимам. Обицм свойством ицдивнтуализированиых режи мов было изыачальное лазыаченне схсмы IIXT мeнеe чем нз 5 ПГЛ. к которым нмелась чу вст вите.лыюсть MET, а также частыс отмены ити замены IIT[] 2-го ряда. В болынилстве случаев пазначение этих режимов было вызвано пзохой нереносимостью тибо отсутствием []'ГII по месту дечения нациентов.
14776 пациентов когорты только $38(8.0 \%)$

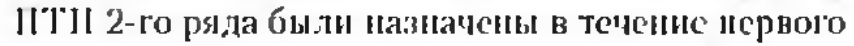
месяla nосле установлени диагыода туберкулеза. У остальны длителыноть лечения 1][1 1-ло

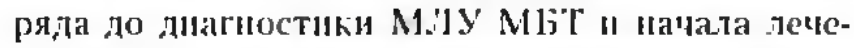
иия резервиыми црецаратами состањляла: 1 мес. II 1 , telu - 3 sec. - y 152 (31.9\%). 3 мec. и I tellb 6 мес - у $128(26.9 \%)$. 6 мес. и 1 . тень - 12 мес. - у 86 
(18.1\%). 12 мec. II 1 лен1 - 24 мсс - y 60 (12.6\%).

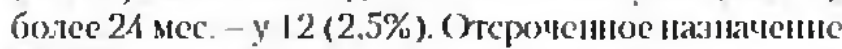
11711 2-10 ряда было свяанио садтержкой выянтени бактерноны деления на 1-6 мес. 11 болtе у части แаแиентов. а также с иснользованщем в 6одынинстве

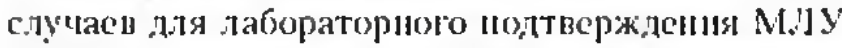

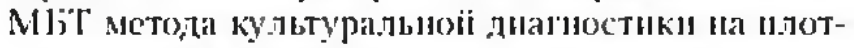

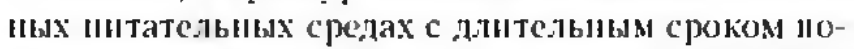

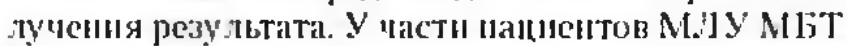
6ы та ирнобретениої в течсин первых 6- 12 мес. лечения туберкулеза. иекоторым [ITI] 2-10 ряда па-

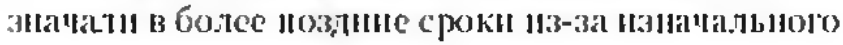
отсутстиня иривержениости к теченико.

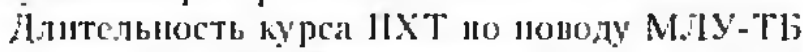

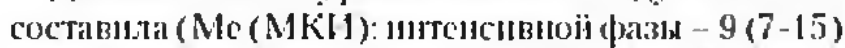
мес. ф)азы продотжения - 12 (9-13) мес. ІІрерывания курса $11 X \mathrm{~T}$ сроками от 2 нел. до $2.5 \mathrm{Mec}$.аренстрировани, у $106(22.3 \%)$ налиентов.

Вынолысын Pl3X у 96/476 (20.2\%) больын. 113 แшх: 66 - cегментарние. бнсементарные. комбнинрованшые резекцин. 28 - лобјктомиї и 2 -

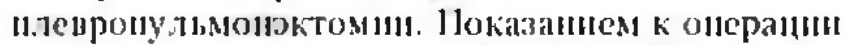
в больинистве случасу (85/96. 88.5\%) служи-

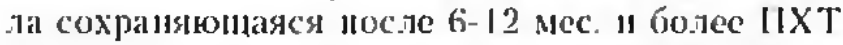

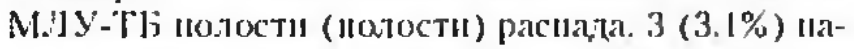

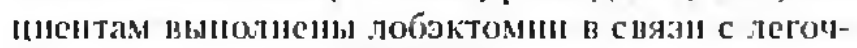

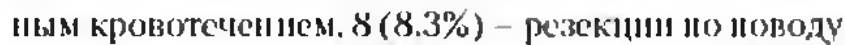
сд)ормнровавнихся туберку лем с расладом. 3 (3.1\%)

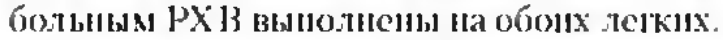

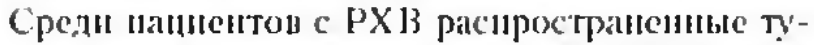

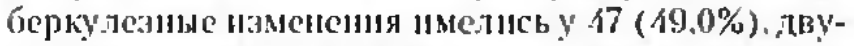

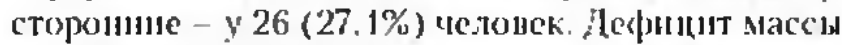

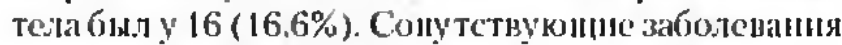

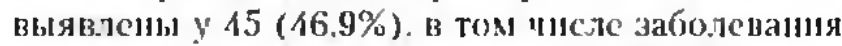

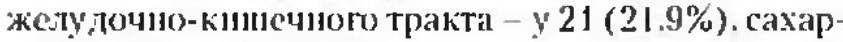

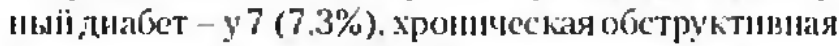

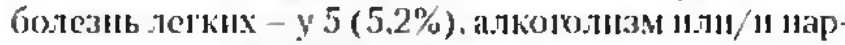

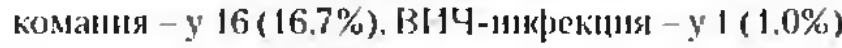

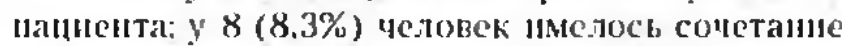
7уух сонутствующих патолониі, у 1 (1,0\%) - трех.

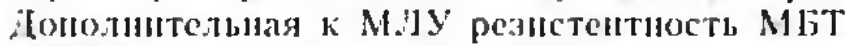

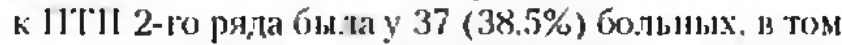

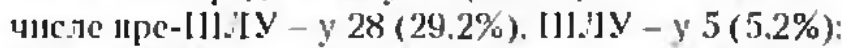
IV к A IITII (מ.ta y 19 (19.8\%), к $5-y 12$ (12.5.\%). k $6-y 4(4.2 \%), \kappa 7-y 3(3.1 \%), k 8-y 1(1.0 \%)$.

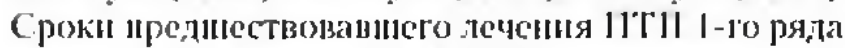
coctanu-in: $<1 \mathrm{Mec}-11(11.5 \%)$ nanuentoв. I Mec. и 1 лень - 3 мес. $-26(27.1 \%)$. 3 мес. 11 I ден -6 мес. I 6 мec. II I денb - $12 \mathrm{sec}$ - 11022 (22.9\%). $12 \mathrm{Mec}$ н 1 , тенl, $-24 \mathrm{sec}-14(14.6 \%)$. $>24 \mathrm{Mcc}-1(1.0 \%)$.

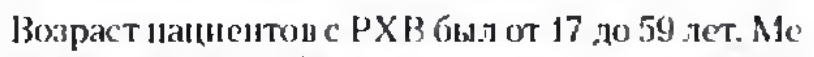

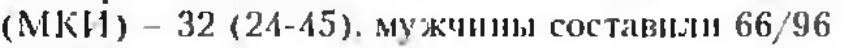
$(68.8 \%)$.

Неносредственые нсходы дечения пациситов ко)орты ॥родемонстрнрованы в таб. 2.13 цејом 11з-

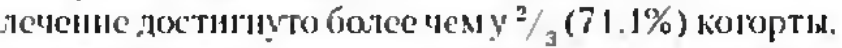

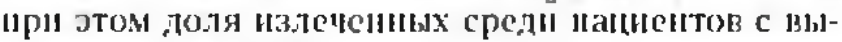

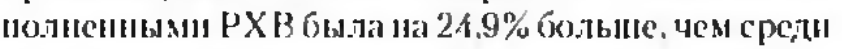
лепеных консервативно. Нотя смертеї в грушие

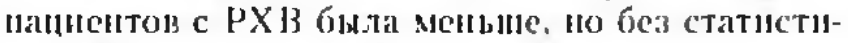

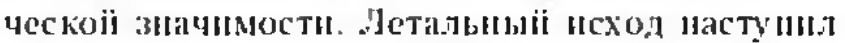

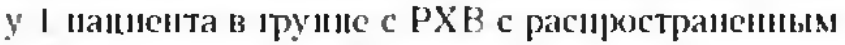
иифильтатнвным туберкулезом лелких, осложиси-

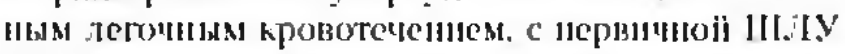

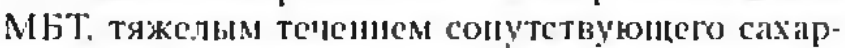

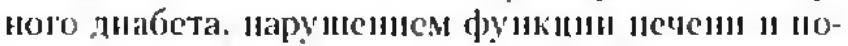
чек. в резу пьтате ирогрессиронания туберку лезиоло upollecca.

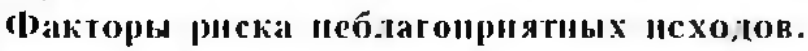
Нз всех рассматриваншихя как џотенщальные d) акторы риска неэф)фективиого лечения зиач1-

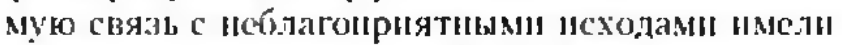
только перечисленин в таб.л. 3. В нх числе ширус-

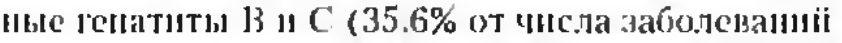

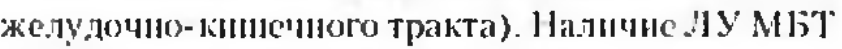

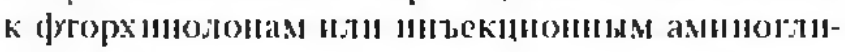
Koзйital.

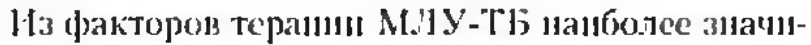

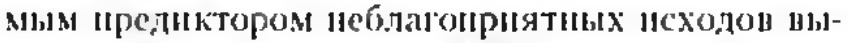

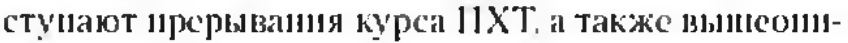

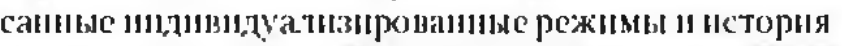

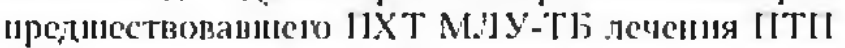
1-ro pяfa cвыne $3 \mathrm{sec} .11$ бotee.

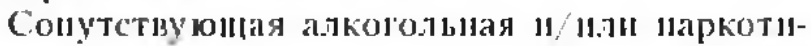

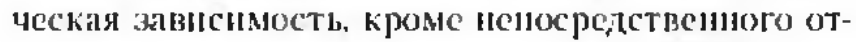

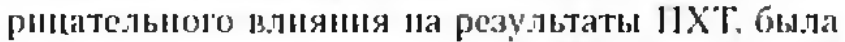

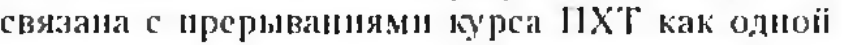

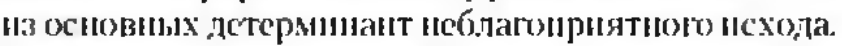

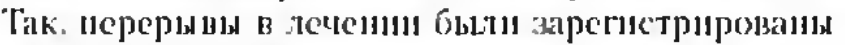

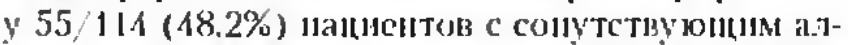

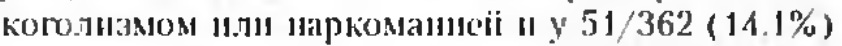

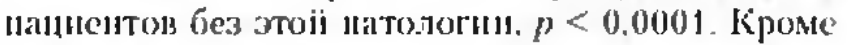

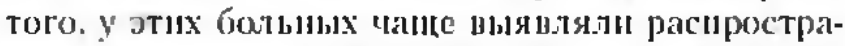
иениые щроцесси (93/11. (81.6\%) ијжотив 203/362

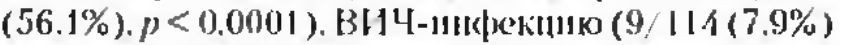
иротив $11 / 362(3.0 \%)$. $p$ - 0.047$)$. заболевания же-

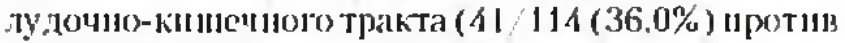
$60 / 362(16.6 \%), p<0.0001)$ : чаџқе возинали แо-

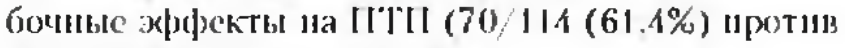
$171 / 362(17.2 \%) . p-0.011)$.

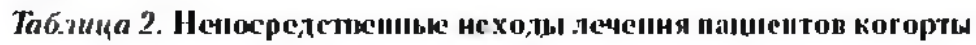

Tabte 2. Immediate iresiment oulcomes in the cohon

\begin{tabular}{|c|c|c|c|c|}
\hline Кеходы гечения & $\begin{array}{c}\text { Все пациенты } \\
\{n=\Delta 76\}\end{array}$ & $\begin{array}{c}\text { Пациенть с PXB } \\
(n=96)\end{array}$ & $\begin{array}{c}\text { Пвциенты оез PXB } \\
(n=380)\end{array}$ & $p$ \\
\hline Излечение & $342(71.8)$ & $88(91,7)$ & $254(66.8)$ & $<0.0001$ \\
\hline Cиерть & $26(5.5)$ & $1(1.0\}$ & $25(6.6)$ & 0.06 \\
\hline
\end{tabular}




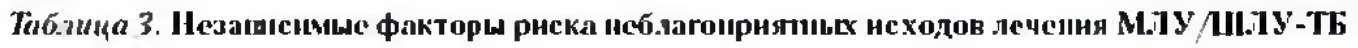

Tabte 3. Independent risk lacion of unfar orable tre alment autcomes of MDR XIJR TB

\begin{tabular}{|c|c|c|c|c|}
\hline \multirow[b]{2}{*}{ Фантор риска } & \multicolumn{2}{|c|}{ Число пациентов. $ก\left({ }^{\circ}\right.$ \% $)$} & \multirow{2}{*}{$\begin{array}{l}\text { ОШ } \\
\text { (95\%-ный ди) }\end{array}$} & \multirow[b]{2}{*}{$D$} \\
\hline & $\begin{array}{c}\text { с излечением } \\
(n=342)\end{array}$ & $\begin{array}{l}\text { с неблагоприятными исхадами } \\
\qquad(n=134)\end{array}$ & & \\
\hline Распространенность ТЕ-происсса > 2 сетментов & $178(52.1)$ & $118(88.1)$ & $6.8(3.9-11.9)$ & $<0.0001$ \\
\hline Положительный результат микроснопии мокроты & $163(47.7)$ & $99(73,9)$ & $3.1(2.0-4.9)$ & $<0.0001$ \\
\hline ВИЧ-инфекция & $9(2.6)$ & 11 (8.2) & $3.3(1.3-8.2)$ & 0.009 \\
\hline Алкоголизм и/или наркомания & $52(15,2)$ & $62(46.3)$ & $4.8(3,1-7.5)$ & $<0.0001$ \\
\hline Сопутствующие заболевания НКТ & $62(18,1)$ & $39(29,1)$ & $1.9(1.2-2.9)$ & 0.009 \\
\hline Прерынания нурса ПХТ & $40(11.7)$ & $66(49.3)$ & $7.3(4.6-11.8)$ & $<0.0001$ \\
\hline Назмвчение индивидуализироіанных схем ПХТ & $60(17.5)$ & $42(31.3)$ & $2.2(1.4-3.4)$ & 0.001 \\
\hline Проживание в сельской местности & $118(34.5)$ & $67(50.0)$ & $1.9(1.3-2.8)$ & 0.002 \\
\hline Нахонденце в местах лишения свободы н анамнезе & $43(12.6)$ & $32(23,9)$ & $2.2(1.3-3.6)$ & 0.003 \\
\hline Доход менее 10000 руб на челопена а семие & $192(56.1)$ & $109(81.3)$ & $3.4(2.1-5.5)$ & $<0.0001$ \\
\hline
\end{tabular}

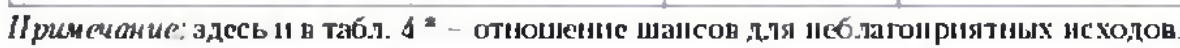

Шроживание в сельскоиі местности как фактор

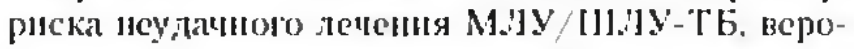
ятно, связано с территорнатьної удатениостью паниентов от фртизнатрическої. в том числе хирурrическої номони. перегулярним обс телованием. иесвоевременноі коррекиие iі $11 \times \mathrm{X}$.

В.тияние резекинониоi хирурнии на нехо, (1) лечения. [Іроведенин іi далее анатогниным методом айлиз обнаружнл, что применение P’X В у папнентов с выненеречнслени ми иреднкторами

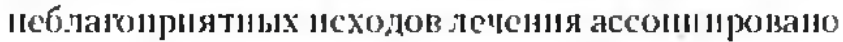
со синжением риска их развития. Результаты сю ириведены в табл. 4. Следуст отметить. пто у 8 па- แнентов с PXßз с неудатеї лечсиня имслось бо-

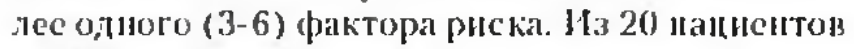

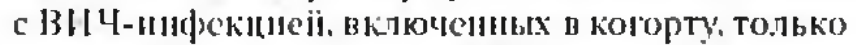
одному было вынолнено PX 13. ито не позволило ировести оненку эф)фектинности РХ В в этої

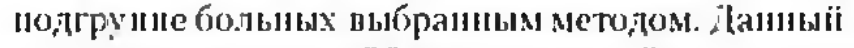
пацнент - мужини 30 лет. лечнвнийіся по поводу инильтратиного туберкулеза обои легких

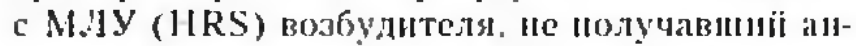
тиретровирусную теранию. Iloлисетентарная резекин но ново ту мнжествениых туберкулем с раснадом была вынолиена носле 15 мес. консерватнвночо лечения. Нсходом курса 11XТ М.IУ-ТБ

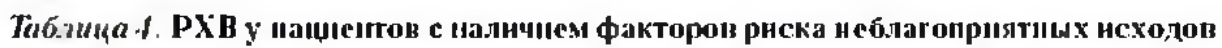

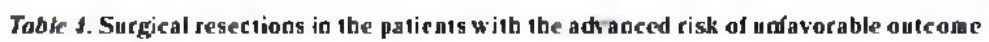

\begin{tabular}{|c|c|c|c|c|}
\hline \multirow{2}{*}{ Подгруппы пациентов } & \multicolumn{2}{|c|}{ Пациенты с истодами } & \multirow{2}{*}{ ОШ' (95\%-ный ДИ) } & \multirow{2}{*}{$\rho$} \\
\hline & излемение & не6лагоприятнщй & & \\
\hline С налинием полостей распада & $76.297(25.6)$ & $8 / 132(6.1)$ & $0.19(0.09-0.4)$ & $<0.0001$ \\
\hline С распространенным Т6-процсссом & $40 / 178(22.5)$ & $7 / 118(5.9)$ & $0.22(0.09-0.5)$ & 0.0004 \\
\hline С полонительным результатом баятериоснопии монроты & $31 / 155(20.0)$ & $3 / 95(3.2)$ & $0.13(0.04-0.44)$ & 0.001 \\
\hline С пре-шлу МБт & $29,93(31.2)$ & $456(7.1)$ & $0.17(0.06-0.51)$ & 0.002 \\
\hline С алкоголизмом'наркоманией & $19 / 62(30.7)$ & $2 / 39(5.1)$ & $0.12(0.03-0.55)$ & 0.007 \\
\hline С заболеваниями НКТ & $55: 190(28.9)$ & $4: 96(4.2)$ & $0.11(0.04-0.3)$ & $<0.0001$ \\
\hline С прерыванием курса ПXТ & $8 / 40(20.0)$ & $2 / 66(3.0)$ & $0.13(0.03-0.61)$ & 0.011 \\
\hline C нестандартными режимами ГXT & $20 ; 60(33.3)$ & $2 / 42(4.8)$ & $0.1(0.02-0.45)$ & 0.003 \\
\hline С начальной ПХТ ПТП 1-го рада > 3 мес. & $1252(23.1)$ & $4 / 62(6.5)$ & $0.23(0.07-0.76)$ & 0.016 \\
\hline Сельсние жители & $34 / 118(28.8)$ & $1,67(1.5)$ & $0.04(0.01-0.28)$ & 0.0014 \\
\hline Находияшиеся в МЛС & $9 / 43(20.9)$ & $1 / 32(3.1)$ & $0.12(0.02-0.99)$ & 0.052 \\
\hline С низким:оченІ низним доходом & $44 / 192(22.9)$ & $5 / 109(4.6)$ & $0.16(0.06-0.42)$ & 0.0002 \\
\hline Вся когорта & $88: 342(25.7)$ & $8 / 134(6,0)$ & $0.18(0.09-0.39)$ & $<0.0001$ \\
\hline
\end{tabular}




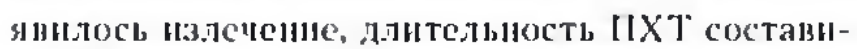

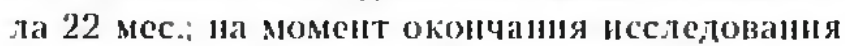

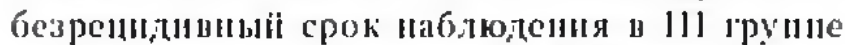

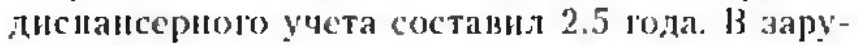
бежноӥ литературе и иастоянце время иредстау-

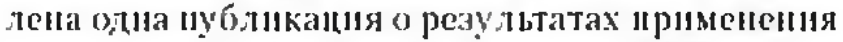

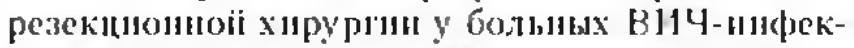

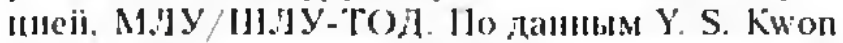

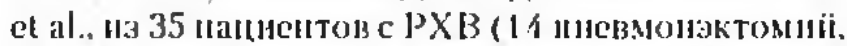

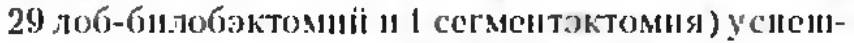

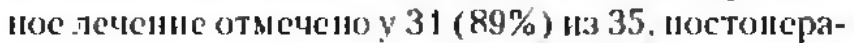

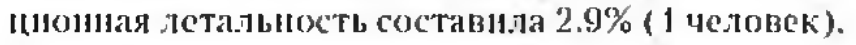

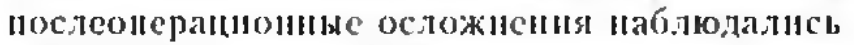
y $10(29 \%)$ 60.16utx |1 11.

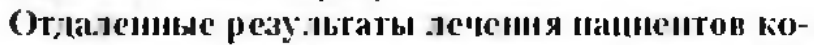
горты. B отдатенHом иерноде иаблюдения срели ж)-

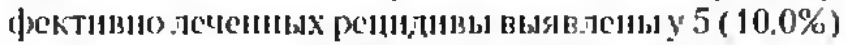

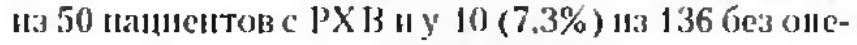

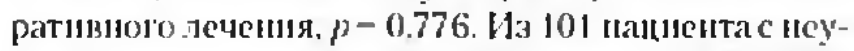

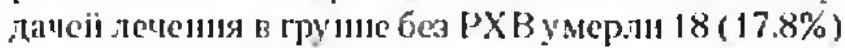

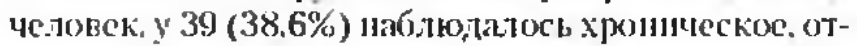

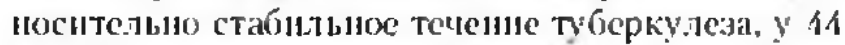

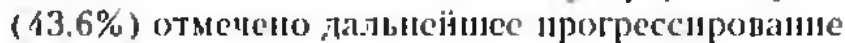
туберкулезиоло щролесса. Среди 7 нсаф)ективно

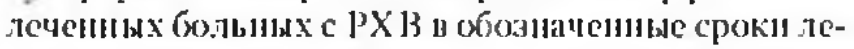

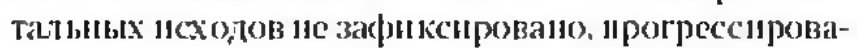

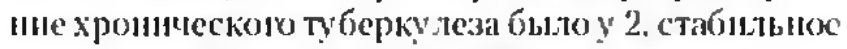
течен11е $-y 5$ челізек $(p-0.19)$.

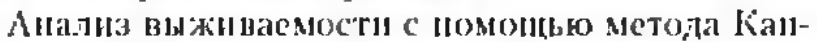

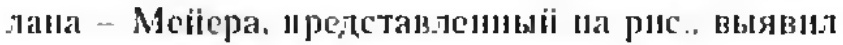

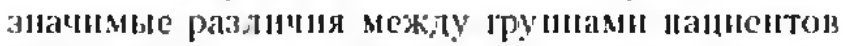
c PX 13 и без таковых. Куму. ая тнвыая выжнњасмость состани.]а 98.6 и $73.8 \%$ соответствен110.

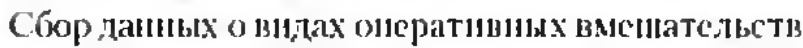
прн туберкулезе с 2009 г. исключен 11з ф)ормы 스 33 rocyдарствениоi статистнческої огчетиости, чro

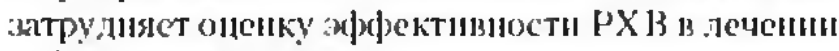
туберкулсза |61. Но и имеюциеся данныс стат нсти-

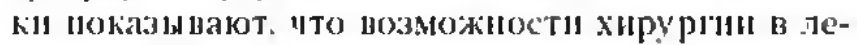
ченин туберку леза испо.льзуются недостаточио. Гак. хирурлические методы внершые выянденыны

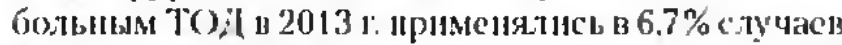

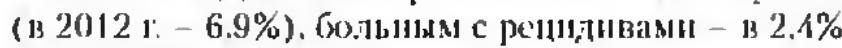

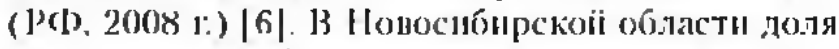

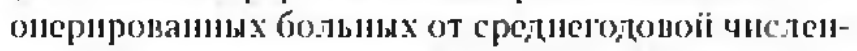
ности (\%).11нах состави.ла $8.9117 .9 \%$ в 2013112012 r. соответствен110 [2|.

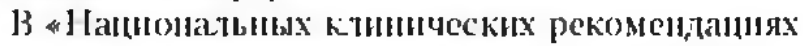
по ирнменснию хирургическнх методов у лечени туберкулеза тенких. разработанынх совместио

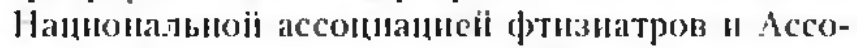

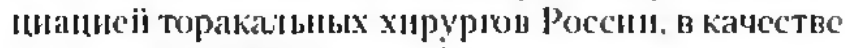

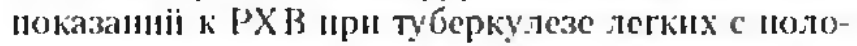

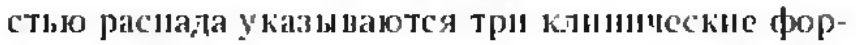

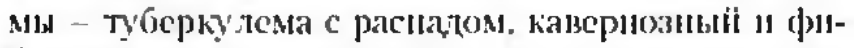
брозио-кавернозиын туберкудез легких и сроки

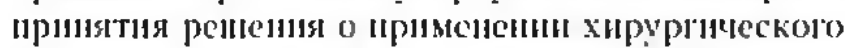
метода - не менес 6 мес. ири натнини бактерновыделения |1]. Вопрос же о расиирени1 показа-

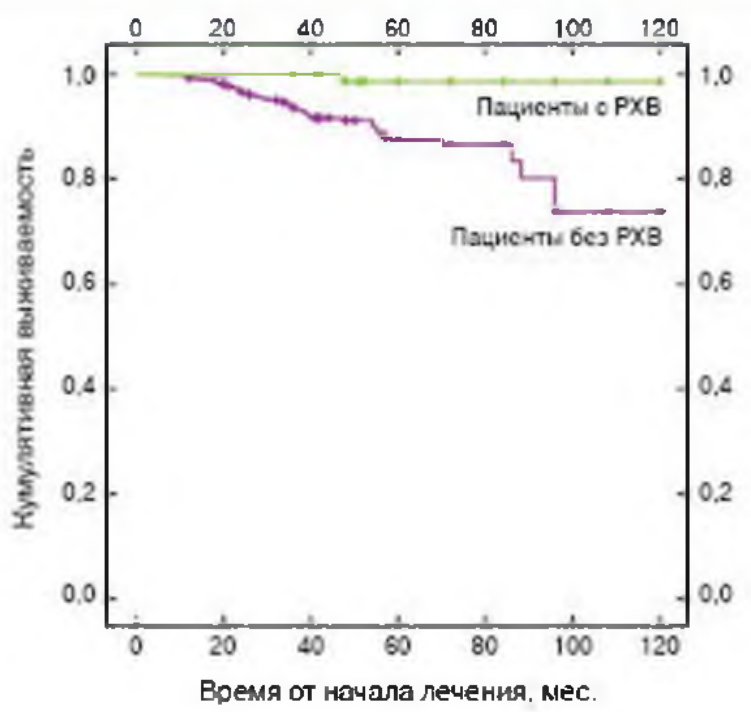

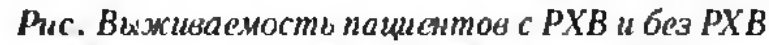
в оmclarжния периоде наблюdения: $p=0.001$ лог-ранговиі критериі: $p=0.001-\kappa$ pumериі Гехана - Брестоу - Виккоксона

Fig. Surizal rate of patients with surgical resection and without it during the pastponed follow-up, $p=0001$ - log-rank tes, $p=0001$ - Cehan - Bresloze - Hilcoxan test

пиї к РХЗ, особенио при туберкулезе с первичиой

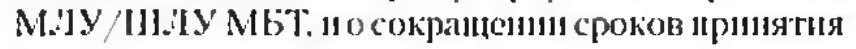

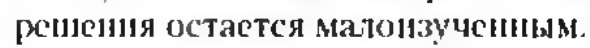

\section{Заключение}

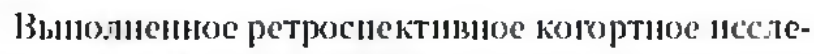

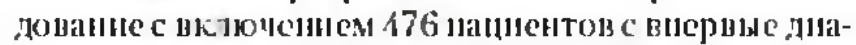

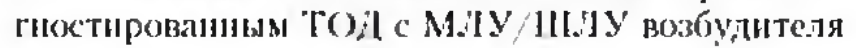
показало. что по результатам законшениого курса

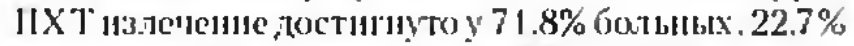
имели исаффектишы курс ПХХТ: 5.5\% умер.ли во время течения. Независимыми иредикторами

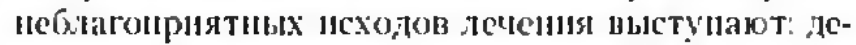
структишые І расыространеные туберку-лезиые

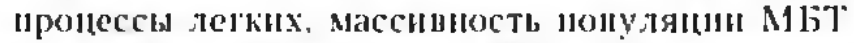
в очаге (очанах) поражения. .ІУ возбудителя тина

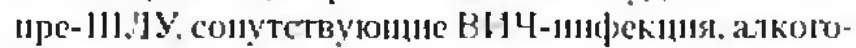
лизм и/1ли наркомания. натология жслудочио-кн-

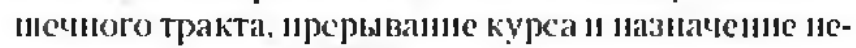

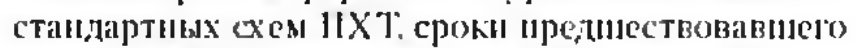

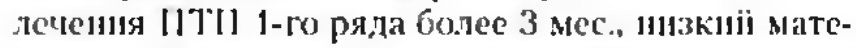

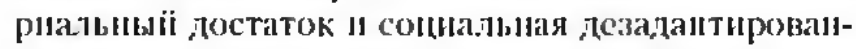

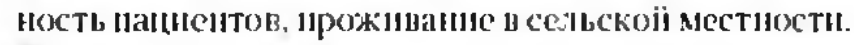

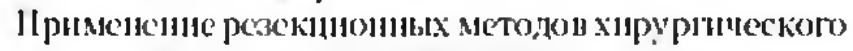

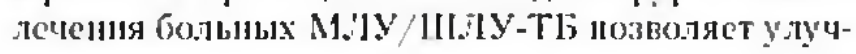

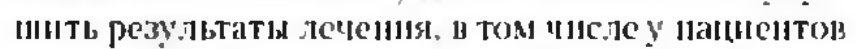
с натичием ()акторов риска неблагонрнатных исxo,

\section{MUTEPATYPA}

1. Национаяьные клинические рекомендации ло прыменению хирурпимегких методов в лелении туберкулеза летких. Национальная ассоинация фтн зиатов. Aссошнашия торакальных хорургов России. 2013. hutp:i/nasph ru/inder/klinicheskie_rekmendacio - 30 
2. Qновные показателы противотуоеркулез ной деягельности в См онрс ком

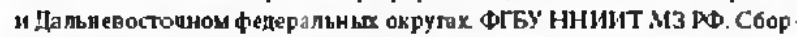
ник тусілиц. - Новогибнртк, 2013. - 89 c

3. Стеляс А. К. и пр. Эффективност хирургичеккото леуения туберкуле3я легких с множес твенной лекарственной устоһ̆ иивог тю в условиях программе DOTS-PLUS // Бюлnетень сионрской медицинь - 2009. 1.- C. $85-93$.

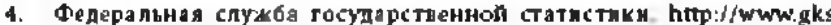

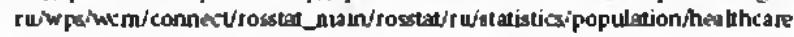

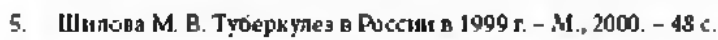

6. Шипова М В. Түберкт̣лез в Россин в2012-2013 3 - М. 2014. - 244 C.

7. Caneti $G$. The 1 Burns Anthersen lecture. Present aspec 5 of bactenal tesistance in tuherculcsis // Am Rev. Respir. Dis. -1965. - Vol. 92 - P. 687-703.

8. Hashour R. Miller J.A new system for grading recommendation in evidence hased guidelines // BM J - 2001. - Vol 323. - P 334336.

9. Kang M. W. et al Surgical tuea ument for multidrug-resistanl and extensive Ar ug-resistant luberc ulosis // Ann. Thoracic Surger y. - 2010. - Vol. 89. No 5. P.1597-1602.

10. Kir A. et al. Adjuvant resectional surgery improves cure sates in multidrug-resistanl tuberculosis// I. Thorac. Cartiovas. Sugery. - 2006. Vol. 131. N 3. - P. $693-696$

11. Kwon Y. S, Kim Y. H , Suh C. Y. et al. Treatment outcomes for HIV-uninféled patients with multidrug-resistan and extensively dr ug-re sistant futerc ulosis / Clin. Infect. Diseases - 2008. - Vol. 47, Ne 4. - P.496-502.

12. Marrone M T. Venkala a mianan V., Goodman M et al Sugioal Interventions for drug-resistant luherc ulosis: a systematic review and meta-analysis // Int. Tuberc. Lung Dis. -2013. - Vol. 17, No 1. - P. 6-16.

13. World Heallh Organization. Clobal Tuberculosis Report 2014 WHO/HTM/TB/20I4.08/ Geneva, 2014 - $118 \mathrm{p}$.

14. World Health Organization. Guidelines tor theprogramnatic management of drug-res istant nuberculosis. WHO/HTM/TBi2008,402 / Geneva, 2008. $247 \mathrm{p}$

15. World Health Organization. The role of surgery in the Is eatment of pulmonary TB and nultids ug- andertensively drug-resistant TBi Genera, 2014 - 23 p.

\section{REFERENCES}

1. Natsionalny klimicheskice rekomendatsij po primeneniy k kirurgichesitikh

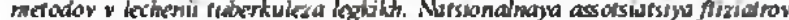

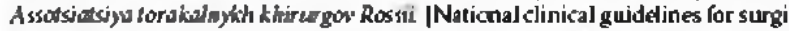
cal Ireatment of pulnicnar y tuherculosis. National Asscalation of TB Doctors Association of Thorade Sugeons of Russia|. 201 3. hrtp:/hasph rulindex'klin. icheskie_rekemiendacii/o-30

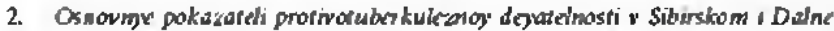
wstochnom ferteralmith olougukt. |Main rales of anti-tubescubsis activilies in Siherian and Far Eastern Federal Districts|. Novosibirsk Tuher-ulosis Research Institute, Russian Ministy of Hed Ith P.uhl., Collation of Tabler, Novositirsk, 2013,89 p.

3. Strelis A.K. et al. Efficiency of surgical uealunent of mulliple trug resistant pulmonary tuherculosis within DOTS Plus Programme. Brdleten' Siburkoy Medtsemy 2009, no. 1, pp. 85-93. (In Russ.)

4. Federal Service of State Statistics. htp://wwwglss.ru/wps/wora/connetiros ataLmain/rostat/nu/atatistics/population/healhcare

5. Shilova M.V. Tuberkulez v Rossi v $1000 \mathrm{~g}$. |Tuberculoris in Russia in 1999 | Marcow, 2000, 48 p.

6. Shilova M.V. Tuberkulez y Rossii y 2012-2013 godu. |Tunerculosis in Russia in 2012-2013]. Moscow, 2014, 244 p.

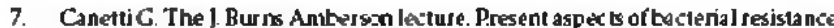
in tuherculosis Am. Rev. Respir. Dis, 1965, sod 92, pp. 687-703.

8. Hasbour $R$, Miller 1 A new system for grading recommendation in evidence hased guidelines $B M /, 2001$, vol 323, pp. 334336

9. Kang M.W. et al. Susgical treatment for muttidug-tesistant and exten sive drug-resistant tuberculosis. Ann. Tharack Stogers 2010, vol 89, no. 5. pp. $1597-1602$

10 Kir A. et al. Adj uvant resecticnal surgery improves cure rales in multidt ug - re sis tant Iuherculosis. J. Thorac Cardionat Sungen, 2006, vol. 131, no, 3, pp. 603-696.
1 1. Kwon Y.S., Kin Y.H., Suh G.Y. et al. Treaument outcomes for HIV-uninfaced patients with mulidrug-ressistant and extensively drug-resistant Iuterculosis. Om. Infert. Diseases, 2008, vol 47, na 4, pp. 496-502.

12. Mar rone .M.T, Venkataramanan V. Goodnan M. et al. Surgical interven lion for drug-resistant tuheralos is a systemalic review and meta-analysis. int. 1. Tuberc. Lung Dis., 201 3, vol 17, no. I, pp.6-16.

13. World Healih Organization. Global Tuherculosis Report 2014. WHO/HTM/TB/2014.08 / Geneva, 2014. 118 p.

14. World Heath Organizalion. Guidelines lor theprcgrammatic managemen of drug-resistant nuberulosis. W'HOVHT M/TB/2008.402/Geneva, 2008. 247 p.

15. World Health Organization. The role of surgery in the trea unent of pulmonary TB and multidrug-andertensively drug-resistant TB/ Genesa, 20 L4. 23 p.

\section{9 КОРРЕС[ОНДЕНЩҢИ}

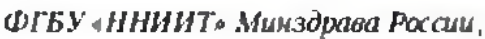

630040, 2. Hosocubupcs, ys. Oxomexas. d. 81 a.

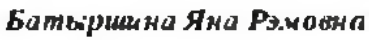

вpa4-6anmepuaro2.

Tes / фanc: 8 (383) 203-78-25, 8 (383) 203-83-62.

E-mail: barirshinammbox.n

Крпснов В.юади.мир.А.лесандрювич

дирекmop.

Tes / фaкс: 8 (383) 203-78-25, 8 (383) 203-83-65.

E-mnil:info(Tnsk-nii m

Петрикио Татьяна Нгореана

заместитель dиректора по мауке.

Tes / qanc: 8 (383)203-83-58. 8 (383) 203-78-25.

E-m ail: tipetrenkorgmail,com

1Locty' 1111.7a 16.03.2015

\section{FOR CORRESPONDENCE}

Nocosibirsk Tuberculosis Research Instinte. Russim Minisin of Henith

81a, Okhorskouna St. Nocasibirsk, 630040

Yana R. Bafyrshinn

Bacienilogis.

Phane/Fai: +7 (383) 203-78-25; +7 (383) 203-83-62

E-mail: bairshinathinbox:n

"'adimir A. Krasyot'

Director.

Phane/Fri: +7 (383) 203-78-25; +7 (383) 203-83-65

E-m nil:infownsk-nitm

Tatiana 1. Petrinko

Depucy Directorfor Resench.

Phone/Fri: +7 (383) 203-83-58; +7 (383) 203-78-25.

E-mail: tipetrenkơngmail.com 